\title{
DIFERENÇAS CULTURAIS, INTERCULTURALIDADE E EDUCAÇÃO EM DIREITOS HUMANOS
}

\author{
Vera Maria Ferrão Candau
}

\begin{abstract}
RESUMO: As questões relativas às diferenças culturais vêm se multiplicando na nossa sociedade, e a consciência dessa realidade é cada vez mais forte entre educadores/as. Entretanto, inúmeras têm sido as pesquisas que identificam, descrevem e denunciam situações em que alunos/as com determinadas marcas identitárias são rejeitados/as, objeto de discriminações e excluídos no cotidiano escolar. Essa realidade nos obriga a afirmar a urgência de se trabalhar as questões relativas ao reconhecimento e à valorização das diferenças culturais nos contextos escolares. Neste sentido, o presente trabalho pretende analisar os diferentes sentidos atribuídos pelos professores aos termos "igualdade" e "diferença", apresentar a perspectiva sobre educação intercultural que vimos construindo nos últimos anos e evidenciar a interrelação entre essas questões e a educação em direitos humanos.
\end{abstract}

Palavras-chave: Diferenças culturais. Educação intercultural. Igualdade-diferença. Educação em direitos humanos.

\section{Cultural differences, interculturality \\ AND EDUCATION IN HUMAN RIGHTS}

\begin{abstract}
Questions that concern cultural differences are multiplying in our society, and more and more educators are getting aware of this reality and its importance. At the same time, there are host of researches which identify, describe and denounce situations where students are rejected, discriminated and excluded in the daily school for having particular identitary signs. This reality let us to pronounce the urgency of thinking over the recognition and valorization of cultural differences in school contexts. This paper intends to analyze the various meanings given by teachers to the words equality and difference, and also to present the perspective about intercultural education elaborated over the last years and to demonstrate the interrelation between these questions and the education in human rights.
\end{abstract}

Key words: Cultural differences. Intercultural education. Equality-difference. Education in human rights.

Doutora e pós-doutora em Educação e professora titular do Departamento de Educação da Pontifícia Universidade Católica do Rio de Janeiro (PUC-Rio). E-mail: vmfc@puc-rio.br 


\section{DifFÉRENCES CULTURELlES, RÉALITÉ INTERCULTURELLE ET ÉDUCATION POUR LES DROITS HUMAINS}

RÉSUMÉ: Les questions concernant la diversité culturelle se sont multipliées dans notre société et la conscience de cette réalité est chaque fois plus forte chez les enseignants. Par ailleurs, de nombreuses recherches permettent d'identifier, de décrire et de dénoncer des situations dans lesquelles des étudiants avec des marques d'identité bien déterminées sont rejetés, ils sont l'objet de discrimination et se trouvent même exclus dans le quotidien scolaire. Cette réalité nous oblige à souligner l'urgence de l'approfondissement des questions relatives à la reconnaissance et à la valorisation positive des différences culturelles dans les contextes scolaires. Cet article se propose, tout d'abord, d'analyser les différentes significations attribuées par les enseignants aux termes "égalité" et "différence" pour ensuite présenter la perspective d'une éducation interculturelle telle que nous l'avons conçue pendant ces dernières années de recherche et, finalement, nous essayons de mettre en évidence l'interrelation entre les questions étudiées et l'éducation pour les droits de l'homme.

Mots-clés: Différences culturelles. Éducation interculturelle. Égalité/différence. Éducation pour les droits humains.

\section{Introdução}

presença de grupos socioculturais diversos nos cenários públicos, tanto
no âmbito internacional como no Brasil, tem provocado tensões, conflitos,
diálogos e negociações orientadas à construção de políticas públicas que focalizem estas questões. Em cada contexto esta problemática adquire uma configuração específica, articulada com as diversas construções históricas e político-culturais de cada realidade.

A afirmação das diferenças - étnicas, de gênero, orientação sexual, religiosas, entre outras - manifesta-se de modos plurais, assumindo diversas expressões e linguagens. As problemáticas são múltiplas, visibilizadas especialmente pelos movimentos sociais que denunciam injustiças, desigualdades e discriminações, reivindicando igualdade de acesso a bens e serviços e reconhecimento político e cultural.

Diferentes manifestações de preconceito, discriminação, diversas formas de violência - física, simbólica, bullying -, homofobia, intolerância religiosa, estereótipos de gênero, exclusão de pessoas deficientes, entre outras, estão presentes na nossa sociedade, assim como no cotidiano das escolas. A consciência desta realidade é cada vez mais forte entre educadores e educadoras. Como afirmou um professor numa das pesquisas que realizamos recentemente, "as diferenças estão bombando na escola".

Entretanto, inúmeros têm sido os estudos e as pesquisas que identificam, descrevem e denunciam situações em que alunos/as com determinadas marcas 
identitárias são rejeitados/as, objeto de discriminações e inferiorizados no dia a dia das nossas escolas.

Neste sentido, gostaria de fazer referência aos resultados da pesquisa, Preconceito e discriminação no ambiente escolar (Mazzon, 2009), realizada pela Fundação Instituto de Pesquisas Econômicas (Fipe), vinculada à Universidade de São Paulo, e apoiada pelo Instituto Nacional de Estudos e Pesquisas Educacionais Anísio Teixeira (Inep). A referida investigação foi coordenada pelo professor José Afonso Mazzon e teve por objetivo analisar de maneira global a incidência de preconceito e discriminação nas escolas públicas, de forma que descrevesse um quadro consolidado que servisse de base para a elaboração de ações globais no campo da promoção da pluralidade cultural. O trabalho compreendeu um estudo quantitativo por meio de um survey aplicado em 500 escolas de todo o país junto a estudantes, professores/as do ensino fundamental e médio, diretores/as, profissionais de educação que atuam nas escolas e pais, mães e responsáveis por alunos/as, que fossem membros do Conselho Escolar ou da Associação de Pais e Mestres. Entre os resultados obtidos, é importante assinalar os altos índices de discriminação e preconceito nas escolas investigadas entre todos os atores e, além disso, o fato que considero de especial relevância para este trabalho, que as escolas nas quais os escores que expressam os níveis de preconceito e práticas discriminatórias apresentam valores mais elevados tendem a apresentar médias mais baixas na Prova Brasil.

Esta realidade obriga a que, se quisermos potencializar os processos de aprendizagem escolar na perspectiva da garantia a todos/as do direito à educação, teremos de afirmar a urgência de se trabalhar as questões relativas ao reconhecimento e à valorização das diferenças culturais nos contextos escolares. Esta proposta supõe, na linha de pesquisa que venho desenvolvendo, incorporar a perspectiva intercultural nos diferentes âmbitos educativos. Esta preocupação não é algo secundário ou que se justapõe às finalidades básicas da escola, mas é inerente a elas.

Neste sentido, o presente trabalho pretende analisar os diferentes sentidos atribuídos pelos professores aos termos "igualdade" e "diferença", apresentar a concepção de educação intercultural que vimos construindo nos últimos anos e evidenciar a inter-relação entre estas questões e a educação em direitos humanos. Quer oferecer elementos que colaborem para a construção de práticas pedagógicas comprometidas com a equidade, a democracia e a afirmação do direito à educação e à aprendizagem de toda criança, de todo adolescente, de toda pessoa humana. Parte da tese de que superar as situações acima mencionadas exige um processo contínuo de desconstrução de aspectos fortemente configuradores da cultura escolar vigente e a promoção de uma educação em direitos humanos na perspectiva intercultural. 


\section{Igualdade? Diferença? Como se situam os professores/as?}

Nos trabalhos de pesquisa que tenho desenvolvido nos últimos anos, a relação entre igualdade e diferença tem sido um foco central. Muitos foram os estudos realizados por diversos membros do grupo de pesquisa, desde 1996. Nesses trabalhos, uma questão se revelou especialmente presente: a polissemia dos termos "igualdade" e "diferença", detectada em entrevistas individuais, grupos focais, observações e narrativas plurais de diferentes educadores e educadoras do ensino fundamental.

Sem dúvida a afirmação de uma professora, "aqui são todos iguais", resposta à pergunta "como você lida com as diferenças na sua sala de aula?", é recorrente e expressão de uma cultura escolar construída sobre a afirmação da igualdade, legado da lógica da modernidade, que impregna os processos educacionais.

A conhecida pesquisadora argentina Emilia Ferreiro (2001) se expressa sobre esta questão e, se referindo ao contexto latino-americano, bem como à dificuldade da escola pública dos nossos países, desde o início de sua institucionalização, de trabalhar com as diferenças, afirma:

A escola pública, gratuita e obrigatória do século XX é herdeira da do século anterior, encarregada de missões históricas de grande importância: criar um único povo, uma única nação, anulando as diferenças entre os cidadãos, considerados como iguais diante da lei. A tendência principal foi equiparar igualdade à homogeneidade. Se os cidadãos eram iguais diante da lei, a escola devia contribuir para gerar estes cidadãos, homogeneizando as crianças, independentemente de suas diferentes origens. Encarregada de homogeneizar, de igualar, esta escola mal podia apreciar as diferenças. (apud Lerner, 2007, p. 7)

De fato, nas narrativas dos professores e professoras, no contexto das pesquisas realizadas, predominavam depoimentos em que esta equivalência entre igualdade e homogeneização era recorrente. A igualdade era concebida como um processo de uniformização, homogeneização, padronização, orientado à afirmação de uma cultura comum a que todos e todas têm direito a ter acesso. Desde o "uniforme" até os processos de ensino-aprendizagem, os materiais didáticos, a avaliação, tudo parece contribuir para construir algo que seja "igual", isto é, o mesmo para todos os alunos e alunas. Nesta perspectiva, certamente impossível de ser alcançada, as diferenças são invisibilizadas, negadas e silenciadas, apresentando os processos pedagógicos um caráter monocultural, marcado pelo que Luisa Cortesão (Cortesão \& Stoer, 1999) intitula de "daltonismo cultural", isto é, a impossibilidade de reconhecer as diferenças culturais presentes no dia a dia das salas de aula. A articulação da afirmação da igualdade com a de sujeito de direitos, básica para o desenvolvimento de processos de educação em direitos humanos, está praticamente ausente das narrativas dos professores entrevistados. 
Quanto ao termo "diferença", nos depoimentos dos educadores, é frequentemente associado a um problema a ser resolvido, à deficiência, ao déficit cultural e à desigualdade. Diferentes são aqueles que apresentam baixo rendimento, são oriundos de comunidades de risco, de famílias com condições de vida de grande vulnerabilidade, que têm comportamentos que apresentam níveis diversos de violência e incivilidade, os/as que possuem características identitárias que são associadas à "anormalidade" e/ou a um baixo capital cultural. Enfim, os diferentes são um problema que a escola e os educadores têm de enfrentar, e esta situação vem se agravando e não sabemos como lidar com ela. Esta é a tônica que predomina nos relatos dos educadores. Somente em poucos depoimentos a diferença é articulada a identidades plurais que enriquecem os processos pedagógicos e devem ser reconhecidas e valorizadas.

Igualdade e diferença constituem, assim, em geral, nas narrativas analisadas, universos semânticos polissêmicos, que se contrapõem, explícita ou implicitamente.

No entanto, considero importante afirmar que a articulação entre igualdade e diferença constitui uma questão que permeia todo o trabalho de pesquisa que venho promovendo, assim como a busca de construção de processos educativos que a tenham no centro de sua dinâmica. Considero que hoje não é possível se trabalhar questões relacionadas à igualdade sem incluir a questão da diferença, nem se pode abordar a questão da diferença dissociada da afirmação da igualdade. De fato, a igualdade não está oposta à diferença, e sim à desigualdade, e diferença não se opõe à igualdade e sim à padronização, à produção em série, à uniformização.

O que estou querendo trabalhar é, ao mesmo tempo, desconstruir a padronização e lutar contra todas as formas de desigualdade presentes na nossa sociedade. Nem padronização, nem desigualdade. A igualdade que quero construir assume o reconhecimento de direitos básicos de todos. No entanto, esses todos não são padronizados, não são os "mesmos". Devem ter as suas diferenças reconhecidas como elemento de construção da igualdade. Diferenças que, como já afirmei, são construções históricas e sociais (Silva, 2000, p. 42) e estão atravessadas por relações de poder. Esta articulação não é simples, nem do ponto de vista teórico, nem das práticas socioeducativas, e está no centro do debate contemporâneo sobre direitos humanos.

\section{Direitos humanos: o debate contemporâneo}

O discurso sobre os direitos humanos tem uma longa trajetória histórica e está intimamente relacionado com as lutas sociais. No entanto, a configuração que adquiriu está fortemente marcada por referenciais da modernidade, tendo no centro 
de sua construção a questão da igualdade, da liberdade e da universalidade. Hoje, vários grupos questionam a pertinência desta construção e se perguntam se esta pode ser referência para se reconhecer as diferenças culturais, os diversos modos de situarse diante da vida, dos valores, as várias lógicas de produção de conhecimento, práticas e visões de mundo.

\section{O professor Antônio Flávio Pierucci, no seu instigante livro Ciladas da diferença} (1999), assim sintetiza esta tensão:

Somos todos iguais ou somos todos diferentes? Queremos ser iguais ou queremos ser diferentes? Houve um tempo que a resposta se abrigava segura de si no primeiro termo da disjuntiva. Já faz um quarto de século, porém, que a resposta se deslocou. A começar da segunda metade dos anos 70, passamos a nos ver envoltos numa atmosfera cultural e ideológica inteiramente nova, na qual parece generalizar-se, em ritmo acelerado e perturbador, a consciência de que nós, os humanos, somos diferentes de fato (...), mas somos também diferentes de direito. É o chamado "direito à diferença", o direito à diferença cultural, o direito de ser, sendo diferente. The right to be different!, como se diz em inglês, o direito à diferença. Não queremos mais a igualdade, parece. Ou a queremos menos, motiva-nos muito mais, em nossa conduta, em nossas expectativas de futuro e projetos de vida compartilhada, o direito de sermos pessoal e coletivamente diferentes uns dos outros. (Pierucci, 1999, p. 7)

O autor parece colocar a questão em termos alternativos: somos iguais ou somos diferentes? Sua tese é a de que até recentemente praticamente nossas lutas tinham como referência fundamental a afirmação da igualdade. $\mathrm{O}$ direito à diferença não tinha ainda aparecido com a força que ele tem hoje. No entanto, atualmente a questão da diferença assume uma importância especial e se transforma num direito, não só o direito dos diferentes a serem iguais, mas o direito de afirmar a diferença em suas diversas especificidades. Pessoalmente, me inclino a defender que certamente há uma mudança de ênfase e uma questão de articulação. Não se trata de afirmar um polo e negar o outro, mas de articulá-los de tal modo que um nos remeta ao outro.

Assumo a posição que afirma a atualidade e a relevância dos direitos humanos, mas acredito, em sintonia com o sociólogo Boaventura Sousa Santos, professor da Universidade de Coimbra, que é necessária uma ressignificação destes direitos na contemporaneidade. Sua tese é de que,

(...) enquanto forem concebidos como direitos humanos universais em abstrato, os Direitos Humanos tenderão a operar como um localismo globalizado, e portanto como uma forma de globalização hegemônica. Para poderem operar como forma de cosmopolitismo insurgente, como globalização contra-hegemônica, os Direitos Humanos têm de ser reconceitualizados como interculturais. (Santos, 2006, p. 441-442)

Para Santos, no contexto da globalização, ou melhor, das globalizações - trata-se de um fenômeno plural -, é possível identificar diferentes movimentos que 
afetam a construção dos direitos humanos. Distingue quatro formas de globalização: localismo globalizado - processo pelo qual determinada realidade local é globalizada com sucesso; globalismo localizado - impacto nas condições locais das práticas transnacionais; cosmopolitismo insurgente e subalterno - resistência organizada transnacionalmente contra os localismos globalizados e os globalismos localizados; e o patrimônio comum da humanidade - emergência das lutas transnacionais por valores ou recursos que são tão globais como o próprio planeta. Ele caracteriza os dois primeiros movimentos como globalização hegemônica, de cima para baixo; e os dois últimos, como globalização contra-hegemônica ou a partir de baixo (idem, ibid., p. 417-421).

A construção dos direitos humanos tem sido feita, segundo o autor, tradicional e hegemonicamente a partir da perspectiva do localismo globalizado. Esta constitui a matriz hegemônica própria da modernidade, claramente presente no expansionismo europeu, portador da "civilização" e das "luzes". É esta a ótica que tem predominado até hoje, com diferentes versões.

No entanto, o desafio atual é reconceitualizá-los a partir da perspectiva do cosmopolitismo insurgente e subalterno, um dos processos, como já afirmei, que caracterizam a globalização que nasce de baixo para cima. Essa globalização surge dos grupos locais, das organizações da sociedade civil, nos movimentos sociais, dos temas que nascem verdadeiramente das inquietudes dos diferentes atores sociais.

Nesse processo de reconceitualização, não se negam as raízes históricas da construção dos direitos humanos, mas se pretende trazê-los para dialogar com a problemática atual e, neste processo, o diálogo intercultural é imprescindível. Esse diálogo vai exigir o desenvolvimento do que ele denomina uma hermenêutica diatópica:

\begin{abstract}
A hermenêutica diatópica baseia-se na ideia de que os topoi [para o autor "os topoi são os lugares comuns retóricos mas abrangentes de determinada cultura, funcionam como premissas de argumentação que, por não se discutirem, dada a sua evidência, tornam possível a produção e a troca de argumentos (2005, p. 447)] de uma dada cultura, por mais fortes que sejam, são tão incompletos quanto a própria cultura a que pertencem (...). O objetivo da hermenêutica diatópica não é, porém, atingir a completude - um objetivo inatingível - mas, pelo contrário, ampliar ao máximo a consciência de incompletude mútua por meio de um diálogo que se desenrola, por assim dizer, com um pé numa cultura e outro noutra. Nisto reside seu caráter diatópico. (Santos, op. cit., p. 448)
\end{abstract}

Para o desenvolvimento do presente trabalho, o que me parece importante assinalar é que a afirmação dos direitos humanos hoje passa pela necessidade de uma ressignificação desses direitos, em que a articulação entre igualdade e diferença e o diálogo intercultural são aspectos fundamentais. Nesta perspectiva, os processos educacionais são de especial relevância. 


\title{
Educação intercultural: construindo um mapa conceitual
}

A educação intercultural tem tido nos últimos anos no continente latino-americano um amplo desenvolvimento, tanto do ponto de vista dos movimentos sociais quanto das políticas públicas e da produção acadêmica. Na revisão bibliográfica que venho realizando sobre o tema, fica evidente que a expressão "educação intercultural" admite diversas leituras, tendo por ancoragem múltiplos referenciais teóricos.

Lopez-Hurtado Quiroz (2007, p. 21-22), especialista nesta temática, faz a seguinte síntese da trajetória de incorporação da educação intercultural na agenda latino-americana:

\begin{abstract}
Nestes 30 anos, desde que o termo foi acunhado na região, a aceitação da noção transcendeu o âmbito dos programas e projetos referidos aos indígenas e hoje um número importante de países, do México à Terra do Fogo, vêm nela uma possibilidade de transformar tanto a sociedade em seu conjunto como também os sistemas educativos nacionais, no sentido de uma articulação mais democrática das diferentes sociedades e povos que integram um determinado país. Desde este ponto de vista, a interculturalidade supõe agora também abertura diante das diferenças étnicas, culturais e linguísticas, aceitação positiva da diversidade, respeito mútuo, busca de consenso e, ao mesmo tempo, reconhecimento e aceitação do dissenso, e na atualidade, construção de novos modos de relação social e maior democracia.
\end{abstract}

Certamente, a educação intercultural tem tido uma trajetória original e plural nos países do continente. Por meio desta citação fica claro que, de um âmbito restrito, a educação escolar indígena, a educação intercultural é concebida hoje como um elemento fundamental na construção de sistemas educativos e sociedades que se comprometem com a construção democrática, a equidade e o reconhecimento dos diferentes grupos socioculturais que os integram.

Tendo presente esta realidade, uma primeira questão que é necessário abordar é a da relação entre multiculturalismo e interculturalidade. Para alguns autores, estes termos se contrapõem, o multiculturalismo sendo visto como a afirmação dos diferentes grupos culturais na sua diferença e o interculturalismo pondo o acento nas inter-relações entre os diversos grupos culturais. Há também aqueles que usam estas palavras praticamente como sinônimos, o termo multiculturalismo sendo mais próprio da produção acadêmica do mundo anglo-saxão e a interculturalidade da dos países de línguas neolatinas, particularmente o espanhol e o francês.

Em diferentes trabalhos venho afirmando que a palavra multiculturalismo é polissêmica, admitindo pluralidade de significados. A necessidade de adjetivá-la evidencia esta realidade. Expressões como multiculturalismo conservador, liberal, celebratório, crítico, emancipador, revolucionário podem ser encontradas na produção sobre o tema e se multiplicam continuamente. No entanto, é possível reduzir a 
diversidade de sentidos atribuídos ao termo multiculturalismo a três fundamentais, que denomino multiculturalismo assimilacionista, multiculturalismo diferencialista e multiculturalismo interativo, também denominado interculturalidade. $\mathrm{O}$ primeiro parte do reconhecimento de que nas sociedades em que vivemos todos os cidadãos e cidadãs não têm as mesmas oportunidades, não existe igualdade de oportunidades. Há grupos, como indígenas, negros, homossexuais, deficientes, pessoas oriundas de determinadas regiões geográficas do próprio país ou de outros países e de classes populares, que não têm o mesmo acesso a determinados serviços, bens, direitos fundamentais que outros grupos sociais, em geral, de classe média ou alta, brancos e pertencentes a grupos com altos níveis de escolarização. Uma política assimilacionista vai favorecer que todos se integrem na sociedade e sejam incorporados à cultura hegemônica. No entanto, não se mexe na matriz da sociedade, procura-se assimilar os grupos marginalizados e discriminados a valores, mentalidades, conhecimentos socialmente valorizados pela cultura hegemônica. No caso da educação, promove-se uma política de universalização da escolarização, todos chamados a participar do sistema escolar, mas sem que se coloque em questão o caráter monocultural presente na sua dinâmica, tanto no que se refere aos conteúdos do currículo quanto às relações entre os diferentes atores, às estratégias utilizadas nas salas de aula, aos valores privilegiados, etc. Quanto ao multiculturalismo diferencialista ou, segundo Amartya Sen (2006), monocultura plural, parte da afirmação de que, quando se enfatiza a assimilação, termina-se por negar a diferença ou por silenciá-la. Propõe então colocar a ênfase no reconhecimento da diferença e, para garantir a expressão das diferentes identidades culturais presentes num determinado contexto, garantir espaços em que estas se possam expressar. Afirma-se que somente assim os diferentes grupos socioculturais poderão manter suas matrizes culturais de base.

No entanto, situo-me na terceira perspectiva, que propõe um multiculturalismo aberto e interativo, que acentua a interculturalidade, por considerá-la a mais adequada para a construção de sociedades democráticas que articulem políticas de igualdade com políticas de identidade e reconhecimento dos diferentes grupos culturais.

Em recente trabalho apresentado no XII Congresso da Association pour la Recherche Interculturelle (ARIC), realizado em Florianópolis, em 2009, Catherine Walsh, professora da Universidad Andina Simon Bolívar (sede do Equador) e especialista no tema, em sua palestra de abertura do evento, distingue três concepções principais de educação intercultural hoje presentes no continente latino-americano. A primeira intitula de relacional e refere-se basicamente ao contacto e intercâmbio entre culturas e sujeitos socioculturais. Esta concepção tende a reduzir as relações interculturais ao âmbito das relações interpessoais e minimiza os conflitos e a assimetria 
de poder entre pessoas e grupos pertencentes a culturas diversas. No que diz respeito às outras duas posições, baseando-se no filósofo peruano Fidel Tubino (2005), a referida autora descreve e discute a interculturalidade funcional e a crítica. Parte da afirmação de que a crescente incorporação da interculturalidade no discurso oficial dos estados e organismos internacionais tem por fundamento um enfoque que não questiona o modelo sociopolítico vigente na maior parte dos países, marcado pela lógica neoliberal excludente e concentradora de bens e poder. Neste sentido, a interculturalidade é assumida como estratégia para favorecer a coesão social, assimilando os grupos socioculturais subalternizados à cultura hegemônica. Este constitui o interculturalismo que qualifica de funcional, orientado a diminuir as áreas de tensão e conflito entre os diversos grupos e movimentos sociais que focalizam questões socioidentitárias, sem afetar a estrutura e as relações de poder vigentes. No entanto, colocar estas relações em questão é exatamente o foco da perspectiva da interculturalidade crítica. Trata-se de questionar as diferenças e desigualdades construídas ao longo da História entre diferentes grupos socioculturais, étnico-raciais, de gênero, orientação sexual, entre outros. Parte-se da afirmação de que a interculturalidade aponta à construção de sociedades que assumam as diferenças como constitutivas da democracia e sejam capazes de construir relações novas, verdadeiramente igualitárias entre os diferentes grupos socioculturais, o que supõe empoderar aqueles que foram historicamente inferiorizados.

Situo-me na perspectiva da interculturalidade crítica. Tendo esta como ponto de partida para os trabalhos que venho realizando, considerei necessário construir, de modo coletivo, no espaço do grupo de pesquisa que coordeno, uma concepção de educação intercultural que servisse de referência comum para os trabalhos da equipe e, com este objetivo, optei pela utilização da perspectiva dos mapas conceituais.

Esta teoria teve sua origem nos anos de 1970, com os trabalhos de Joseph Novak, pesquisador estadunidense, especialista em psicologia cognitiva. Tem por base a teoria da aprendizagem significativa de David Ausubel. Novak concebe os mapas conceituais como ferramentas cujo principal objetivo é organizar e representar o conhecimento. Os mapas conceituais têm sido utilizados para diferentes finalidades: organização de sequências de aprendizagem, estratégias de estudo, construção de instrumentos de avaliação escolar, realização de pesquisas educacionais, entre outras.

Segundo Novak e Cañas (2004), os mapas conceituais são estruturados a partir de conceitos fundamentais e suas relações. Usualmente, os conceitos são destacados em caixas de texto. A relação entre dois conceitos é representada por uma linha ou seta, contendo uma palavra ou frase de ligação. Esta ferramenta está orientada a reduzir e concentrar a estrutura cognitiva subjacente a um dado 
conhecimento, visibilizando os elementos básicos dessa estrutura e permitindo analisar seus elementos fundamentais.

Tendo esta perspectiva como referência, contruímos coletivamente um mapa conceitual da expressão "educação intercultural". A questão focal que orientou nossos trabalhos foi: em que consiste a educação intercultural? Com este ponto de partida, e a concepção crítica como referência, durante o primeiro semestre de 2009, realizamos encontros semanais em que fomos trabalhando coletivamente as diferentes etapas do desenvolvimento do mapa conceitual.

O passo fundamental consistiu em definir as categorias básicas. Depois de vários encontros, chegamos a assumir consensualmente que eram as seguintes: sujeitos e atores, saberes e conhecimentos, práticas socioeducativas e políticas públicas.

A primeira categoria, sujeitos e atores, refere-se à promoção de relações tanto entre sujeitos individuais quanto entre grupos sociais integrantes de diferentes culturas. A interculturalidade fortalece a construção de identidades dinâmicas, abertas e plurais, assim como questiona uma visão essencializada de sua constituição. Potencializa os processos de empoderamento, principalmente de sujeitos e atores inferiorizados e subalternizados, e a construção da autoestima, assim como estimula os processos de construção da autonomia num horizonte de emancipação social, de construção de sociedades onde sejam possíveis relações igualitárias entre diferentes sujeitos e atores socioculturais.

Quanto à categoria de saberes e conhecimentos, convém ter presente que há autores que empregam estes termos como sinônimos, ao passo que outros os diferenciam e problematizam a relação entre eles. O que denominam conhecimentos está constituído por conceitos, ideias e reflexões sistemáticas que guardam vínculos com as diferentes ciências. Esses conhecimentos tendem a ser considerados universais e científicos, assim como a apresentar um caráter monocultural. Quanto aos saberes, são produções dos diferentes grupos socioculturais, estão referidos às suas práticas cotidianas, tradições e visões de mundo. São concebidos como particulares e assistemáticos.

Com Koff (2009, p. 61), considero que, "na discussão se os termos saber e conhecimento são sinônimos ou não, podem ou não ser usados indistintamente, o mais importante é considerar a existência de diferentes saberes e conhecimentos e descartar qualquer tentativa de hierarquizá-los". Neste sentido, a perspectiva intercultural procura estimular o diálogo entre os diferentes saberes e conhecimentos, e trabalha a tensão entre universalismo e relativismo no plano epistemológico, assumindo os conflitos que emergem deste debate.

A categoria práticas socioeducativas, referida à interculturalidade, exige colocar em questão as dinâmicas habituais dos processos educativos, muitas vezes padronizadores e uniformes, desvinculados dos contextos socioculturais dos sujeitos que 
deles participam e baseados no modelo frontal de ensino-aprendizagem. Favorecem dinâmicas participativas, processos de diferenciação pedagógica, a utilização de múltiplas linguagens e estimulam a construção coletiva.

A quarta categoria, políticas públicas, aponta para as relações dos processos educacionais com o contexto político-social em que se inserem. A perspectiva intercultural crítica reconhece os diferentes movimentos sociais que vêm se organizando, afirmando e visibilizando questões identitárias. Defende a articulação entre políticas de reconhecimento e de redistribuição, não desvinculando as questões socioeconômicas das culturais e apoia políticas de ação afirmativa orientadas a fortalecer processos de construção democrática que atravessem todas as relações sociais, do micro ao macro, na perspectiva de uma democracia radical.

Tendo presente as categorias básicas do mapa conceitual e as subcategorias propostas para cada uma delas, passou-se a propor palavras de ligação entre elas. Uma vez construídas as categorias e subcategorias, foi montada a síntese do mapa conceitual, que apresento em anexo. Certamente o mapa conceitual elaborado pode ser expandido, discutido e complexificado.

\section{Educação intercultural e direitos humanos: construindo caminhos}

Estamos como educadores e educadoras desafiados/as a promover processos de desconstrução e de desnaturalização de preconceitos e discriminações que impregnam, muitas vezes com caráter difuso, fluido e sutil, as relações sociais e educacionais que configuram os contextos em que vivemos. A naturalização é um componente que faz em grande parte invisível e especialmente complexa esta problemática, que invade e povoa nossos imaginários individuais e sociais em relação aos diferentes grupos socioculturais. Trata-se de questionar esta realidade. Também é fundamental desvelar e questionar os sentidos de igualdade e diferença que permeiam os discursos educativos. Outro aspecto imprescindível é problematizar o caráter monocultural e o etnocentrismo que, explícita ou implicitamente, estão presentes na escola e impregnam os currículos escolares. Perguntar-nos pelos critérios utilizados para selecionar e justificar os conteúdos escolares. Desestabilizar a pretensa "universalidade" dos conhecimentos, valores e práticas que configuram as ações educativas e promover o diálogo entre diversos conhecimentos e saberes. Estamos desafiados também a reconhecer e valorizar as diferenças culturais, os diversos saberes e práticas, e a afirmar sua relação com o direito à educação de todos. Reconstruir o que consideramos "comum" a todos e todas, garantindo que nele os diferentes sujeitos socioculturais se reconheçam, possibilitando assim que a igualdade se explicite nas diferenças que são assumidas como comum referência, rompendo dessa forma com o caráter monocultural da cultura escolar. Outro aspecto que considero 
fundamental se relaciona com o resgate dos processos de construção das identidades culturais, tanto no nível pessoal como coletivo. Um elemento importante nesta perspectiva são as histórias de vida dos sujeitos e das diferentes comunidades socioculturais. É importante que se opere com um conceito dinâmico e histórico de cultura, capaz de integrar as raízes históricas e as novas configurações, evitando-se uma visão das culturas como universos fechados e em busca do "puro", do "autêntico" e do "genuíno", como uma essência preestabelecida e um dado que não está em contínuo movimento. Um último núcleo de desafios que gostaria de assinalar tem como eixo fundamental promover experiências de interação sistemática com os "outros": para sermos capazes de relativizar nossa própria maneira de situarmo-nos diante do mundo e atribuir-lhe sentido, é necessário que experimentemos uma intensa interação com diferentes modos de viver e se expressar. Não se trata de momentos pontuais, mas da capacidade de desenvolver projetos que suponham uma dinâmica sistemática de diálogo e construção conjunta entre diferentes pessoas e/ou grupos de diversas procedências sociais, étnicas, religiosas, culturais, etc. Também estamos chamados a favorecer processos de "empoderamento", tendo como ponto de partida liberar a possibilidade, o poder, a potência que cada pessoa, cada aluno, cada aluna tem para que possa ser sujeito de sua vida e ator social. O "empoderamento" tem também uma dimensão coletiva, apoia grupos sociais minoritários, discriminados, marginalizados, etc., favorecendo sua organização e participação ativa em movimentos da sociedade civil. As ações afirmativas são estratégias que se situam nesta perspectiva. Visam a melhores condições de vida para os grupos marginalizados, à superação do racismo, da discriminação de gênero, de orientação sexual e religiosa, assim como das desigualdades sociais.

\section{Considerações finais}

Retomo o início do nosso trabalho. Manifestações de preconceito, discriminação e violência se multiplicam em número crescente em muitas de nossas escolas. Desafiam as práticas habituais do cotidiano escolar. Como educadores e educadoras ficamos perplexos/as e muitas vezes nos sentimos impotentes. Algumas iniciativas são tomadas, de caráter pontual, dirigidas a grupos determinados, em momentos específicos do ano escolar, projetos que abordam temas concretos são implementados. Mas os desafios permanecem e, em muitos casos, se agravam.

Neste texto, defendo a tese de que é a lógica que configura a cultura escolar que temos de desconstruir e reconstruir, se queremos trabalhar em profundidade esta problemática. Trata-se de promover uma educação em direitos humanos na perspectiva intercultural crítica que afete todos os atores e as dimensões do processo educativo, assim como os diferentes âmbitos em que ele se desenvolve. 
Trata-se de uma tarefa de longo prazo, mas, ao mesmo tempo, podemos colocá-la em prática hoje, no nosso contexto educacional específico. De fato, já existem muitos educadores e educadoras comprometidos/as com ela. Estamos convidados/ as a fortalecer esta ação coletiva, na nossa escola e nos movimentos sociais. Sabemos que a escola não é onipotente. Mas acredito que, articulando suas ações com as de outros atores sociais, muito poderemos contribuir para a construção de uma educação e de uma sociedade mais igualitárias e democráticas.

\section{Referências}

CORTESÃO, L.; STOER, S. "Levantando a pedra": da pedagogia inter/multicultural às políticas educacionais numa época de transnacionalização. Porto: Afrontamento, 1999.

KOFF, A.M.N.S. Escolas, conhecimentos e culturas: trabalhando com projetos de investigação. Rio de Janeiro: 7 letras, 2009.

LERNER, D. Ensenãr en la diversidad; conferencia dictada en las Primeras Jornadas de Educación Intercultural de la Provincia de Buenos Aires, La Plata, 28 de junio de 2007. Lectura y Vida, Buenos Aires, v. 26, n. 4, p. 6-17, dez. 2007.

LOPEZ-HURTADO QUIROZ, L.E. Trece claves para entender la interculturalidad en la educación latinoamericana. In: PRATS, E. (Coord.). Multiculturalismo y educación para la equidad. Barcelona: Octaedro-OEI, 2007. p. 13-44.

MAZZON, J.A. (Coord.). Preconceito e discriminação no ambiente escolar. São Paulo: FIPE/USP; Brasília, DF: Inep, 2009.

NOVAK, J.; CAÑAS, A. Building on new constructivist ideas and map tools to create a new model for education. In: NOVAK, J.; CAÑAS, A.; GONZÁLES, F.M. (Ed.). Proceedings of the First International Conference on Concept Mapping. Pamplona: Universidad Publica de Navarra, 2004. Disponível em: <http://cmc.ihmc.us/papers20040285>. Acesso em: 7 jan. 2009.

PIERUCCI, A.F. Ciladas da diferença. São Paulo: Editora 34, 1999.

SANTOS, B.S. (Org.). A gramática do tempo: para uma nova cultura política. São Paulo: Cortez, 2006.

SEN, A. O racha do multiculturalismo. Folha de S. Paulo, São Paulo, 17 set. 2006. Caderno Mais.

SILVA, T.T. Teoria cultural e educação. Belo Horizonte: Autêntica, 2000. 
TUBINO, F. La interculturalidad crítica como proyecto ético-político. In: ENCUENTRO CONTINENTAL DE EDUCADORES AGUSTINOS, 2005, Lima. Anais eletrônicos... Disponível em: <http://oala.villanova.edu/congresos/educación/lima-ponen-02.html >. Acesso em: 15 out. 2009.

WALSH, C. Interculturalidad y (de)colonialidad: perspectivas críticas y políticas. In: CONGRESO DA ASSOCIATION POUR LA RECHERCHE INTERCULTURELLE, 12., 2009, Florianópolis. Anais... Florianópolis: UFSC, 2009.

Recebido em 7 de fevereiro de 2011.

Aprovado em 17 de maio de 2011. 


\section{ANEXO}

\section{Educação intercultural: mapa conceitual}

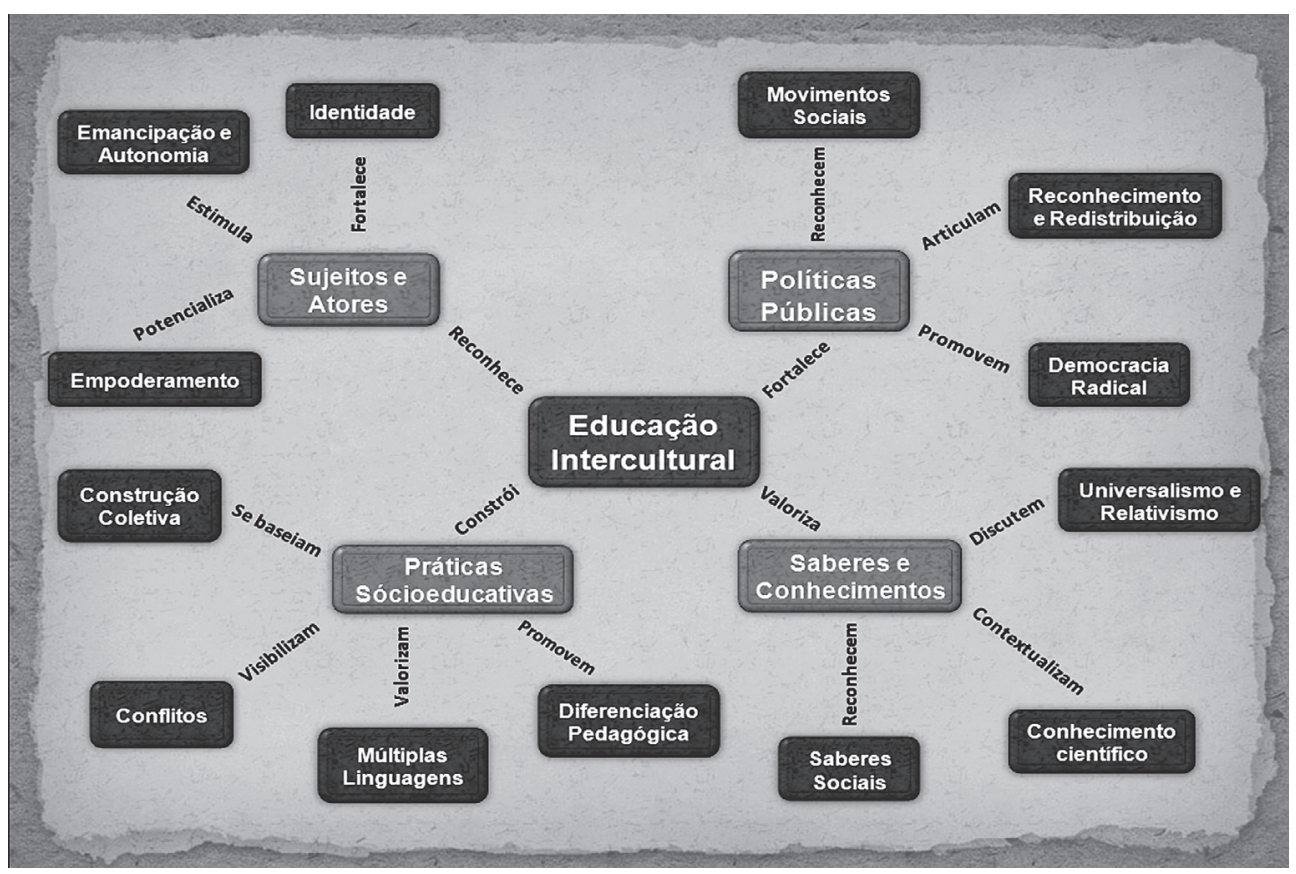

